\title{
AFECTOS ESQUIVOS: UNA ESTÉTICA PARA UNA POLÍTICA
}

\author{
POR \\ Ana María Amar SÁnchez \\ University of California-Irvine
}

Las relaciones entre literatura y política siempre han sido objeto de atención y debate por parte de la crítica; de algún modo, cuando se interesa por este vínculo con frecuencia queda en segundo plano la cuestión estética. De hecho, un corpus construido a partir de esta perspectiva suele dejar de lado las disímiles cualidades literarias de cada texto que lo conforma; es decir, la elección de los mismos se determina con independencia de los valores estéticos de cada caso particular. Aunque pueda haber entre ellos notables diferencias y por más que sea posible establecer distinciones que van de la sutileza y complejidad de un cuento de Borges a la novela más convencional, todos pueden ser funcionales para el enfoque elegido.

Justamente esas disímiles cualidades literarias, así como las nuevas formas en los relatos recientes de plantear el nexo con lo político, llevan a pensar las relaciones que sostienen con la estética; es decir, parece imponerse una reflexión que incorpore los problemas y tensiones entre los tres términos: literatura, política y estética. $\mathrm{Si}$, como afirma Rancière, "no hay ningún conflicto entre la pureza del arte y su politización. Al contrario, en función de su pureza la materialidad del arte se propone como materialidad anticipada de una configuración distinta de la comunidad" (Sobre políticas 27), podemos pensar que la literatura, ya sea en sus formas más explícitas o más elusivas, intenta "una configuración diferente". La cuestión será cómo diseña esas configuraciones, qué tipo de soluciones encuentra al intento de fusionar lo político con una forma estética específica. ${ }^{1}$ En otro estudio reciente, "Las paradojas del arte político", Rancière sostiene que "un arte crítico es un arte que sabe que su efecto político pasa por la distancia estética" (84), es decir, "lo que se llama política del arte es el entrelazamiento de lógicas heterogéneas" (66).

Coincido con Donoso Macaya quien también cita a Rancière en su estudio sobre Bolaño y señala que "es posible percibir la existencia de un territorio común a la literatura y a la política: ese territorio común es el territorio de la estética" (126). 
Me enfocaré aquí en textos literarios que no se plantean abiertamente como una narrativa política -al menos de un modo tradicional-; por el contrario, en ellos parecen primar las preocupaciones estéticas y, sin embargo, sus modos de representación proponen una lectura y un rechazo de los resultados de las transformaciones históricosociales del siglo XX. Es decir, me pregunto cómo leer lo político, a través de qué mecanismos, cómo puede leerse una evaluación de la historia política que desemboca en nuestro presente en una narrativa que no hable de los hechos, pero que nos permita pensar en ellos y en sus consecuencias. Voy a considerar las obras de dos autores aparentemente distantes entre sí y pertenecientes a mundos culturales, geográficos y políticos muy diferentes: la narrativa del uruguayo Mario Levrero -en particular La novela luminosa (2005) - y la producción del puertorriqueño Eduardo Lalo -en especial Países invisibles (2008)-. ${ }^{2}$ Estos relatos dan cuenta de esos procesos de modos diversos y "sesgados", producen desplazamientos y rupturas con los sistemas canónicos de representación de lo político, plantean un desapego, una desilusión y un rechazo que hace a los personajes protagonistas casi "invisibles" en un mundo en el que indudablemente no se sienten cómodos.

Sorprenden las estrategias comunes en estas manifestaciones surgidas en ámbitos culturales que suelen verse como muy distantes y disímiles uno del otro. No obstante, muchos textos pertenecientes a la literatura latinoamericana han dialogado desde siempre y establecido múltiples redes entre sí, lo que permite analizar aquellos gestos compartidos que delatan similares preocupaciones y problemáticas. En este caso, ambos no sólo comparten la cercanía temporal sino que coinciden en ser un tanto "inclasificables" por su imprecisa condición genérica y por un uso de la voz narrativa igualmente compleja y ambigua. Tanto el lector de Países invisibles como el de La novela luminosa pueden notar un uso y una mezcla muy libre y compleja de diversos géneros: Países invisibles es un ensayo, un diario, quizá una ficción-de hecho el narrador se pregunta “¿Hasta qué punto esto es una novela?” (150)-. La pregunta también vale para La novela luminosa, un proyecto de novela construido, en su mayor parte, como un diario, que tal vez puede ser también un ensayo. La articulación o fusión de formas hace borrosa en los dos casos la adscripción a un género preciso e impide encasillar los textos. Del mismo modo, otras estrategias narrativas coinciden: en especial, los narradores-protagonistas juegan con el mismo efecto de "confusión" o mezcla entre lo real y lo referencial. En ambos, los datos que el lector posee de los autores funcionan como un guiño, generan algo similar a lo que Manuel Alberca y Alicia Molero de la

2 Aunque La novela luminosa es el centro de la argumentación de este trabajo, es fundamental recordar que continúa de alguna manera sus textos previos "Diario de un canalla" (1992) y El discurso vacío (1996), y está vinculada con su colección de notas periodísticas Irrupciones (editadas en 2007); lo mismo vale para el nexo que une Países invisibles con un texto anterior, donde (2005), y con Simone, publicado tres años después.

Revista Iberoamericana, Vol. LXXXII, Núm. 257, Octubre-Diciembre 2016, 805-818 ISSN 0034-9631 (Impreso) 
Iglesia llaman "autoficción", Santiago Morales-Rivera "simulacro autobiográfico" y Julio Premat "ficción de autor". ${ }^{3}$ Se trata de un gesto cómplice muy claro al que Alberca denomina un pacto ambiguo y que se manifiesta en este caso en la coincidencia de nombres entre narrador y autor; se advierte en Países invisibles: "De ahí que el lector tenga, por lo que pueda valer, un fragmento de ese ser de papel y tinta que es Eduardo Lalo" (129). A su vez, Levrero remite en su novela a la otra parte de su nombre real: "le explico también que yo soy Jorge Varlotta" (147). ${ }^{4}$

Es decir, en ambos casos, y más allá de las diferencias entre las estéticas a las que pertenecen los relatos, encontramos un sujeto narrador complejo, problemático, punto de cruce entre ficción y referencialidad y, posiblemente -y ésta es mi hipótesis-, punto de cruce entre política y estética, entre referencia y autorreferencia. ${ }^{5}$ La reiteración de esta figura que parece fusionar autor/narrador/personaje en mucha de la narrativa de los últimos años no implica, por supuesto, volver a la categoría de "autor" tradicional, sino analizar el sentido y función de esta compleja y peculiar figura a la que Premat, en el trabajo antes mencionado, considera un espacio para "proponer soluciones dinámicas" donde se construye "una coherencia, una dialéctica identitaria del que escribe"(12). Sin negar esta postura, creo que en la narrativa reciente, ese espacio es un lugar esencial donde poner en escena y representar la tensión entre política y textualidad.

Este sujeto funciona como un ámbito privilegiado, como un signo que señala, a la vez, hacia la escritura y hacia la referencia. Por una parte, a través de esa enunciación el texto se plantea como escritura, y el narrador de Lalo insiste en el hacer que lo ocupa: "¿Qué género es uno sin fronteras? ¿No será ya, de entrada, una incursión en lo novelístico el hecho de que este texto aborde como objeto de estudio la invisibilidad?" (150) y en Levrero leemos "para el lector común, tal vez este diario podría pasar por una novela, con un protagonista y unas situaciones inventadas por mí" (353) y más adelante "la forma más adecuada de resolver la novela luminosa es la autobiográfica" (436). ${ }^{6}$ Asimismo, ambos textos están atravesados por los comentarios acerca de libros,

3 Numerosos estudios avalan en los últimos años el interés de la crítica contemporánea -y de la teoríapor esta estrategia narrativa: los trabajos citados de Premat, Alberca, Molero de la Iglesia y MoralesRivera están dedicados en especial a la literatura latinoamericana y española.

4 Su nombre completo era Jorge Mario Varlotta Levrero; publicó sus novelas y cuentos con el nombre de Mario Levrero y la mayoría de los textos periodísticos, de humor y las historietas con el de Jorge Varlotta.

5 El desarrollo de este aspecto excede el propósito de este trabajo, pero quisiera señalar que es particularmente interesante en la medida en que se ha vuelto frecuente en la literatura contemporánea, donde esta estrategia plantea un nuevo juego de "ficción-realidad" con el que parece cuestionar las perspectivas ya aceptadas sobre las categorías de narrador y autor.

6 Ya en el final del texto de Levrero, "Epílogo del diario", leemos: "Me hubiera gustado que el diario de la beca pudiera leerse como una novela; tenía la vaga esperanza de que todas las líneas argumentales abiertas tuvieran alguna forma de remate. Desde luego, no fue así, y este libro, en su conjunto, es una muestra o un museo de historias inconclusas" (537).

Revista Iberoamericana, Vol. LXXXII, Núm. 257, Octubre-Diciembre 2016, 805-818 ISSN 0034-9631 (Impreso)

ISSN 2154-4794 (Electrónico) 
libros comprados, leídos y/o no comprados y deseados; de hecho, el fragmento "El experimento" en Lalo se refiere a eso precisamente, a leer pero sin comprar libros. En cualquier caso los libros atraviesan los dos relatos, se comentan, se admiran o rechazan: leer y escribir es el espacio -casi el único espacio-por donde estos sujetos narradores se desplazan con comodidad. Esa figura está entonces profundamente unida a la escritura, revierte sobre la especificidad textual, obliga a atender a la situación de enunciación (no hay que olvidar, por otra parte, la atención a lo que podríamos llamar el "espesor" de esa escritura que dan ambos autores a sus trabajos). A su vez, esta construcción autoral, esta autoficción sería la "vía de salida", el vaso comunicante con el "afuera", donde se inscribe la política en textos en los que no se narran hechos puntuales, sucesos o acontecimientos históricos precisos y que, incluso, parecen eludirlos. A través de "esa voz que enuncia" de los narradores, se representa un mundo exterior al que rechazan por igual ambos relatos y en el que es fundamental la oposición planteada por Lalo entre "lo visible" versus "lo invisible": hay que recordar que los países invisibles son "aquellos que han sido intervenidos por el discurso del Otro y Éste habló y habla por ellos" (31). "Esta polaridad vale también para Levrero; de hecho, la dedicatoria ("Al país invisible") y el epígrafe ("Mi reino es el exilio") del primero podrían usarse en el segundo: el "poder de la no-participación, el poder de la invisibilidad" (139) al que se refiere Lalo podría ser el motor que mueve al autor del diario en la obra de Levrero. Asimismo, esta oposición vale tanto para los países (ambos autores y textos pertenecen a países igualmente invisibles para el Primer Mundo) como para los sujetos. Ser visible, ver, ser visto, no querer ver son los términos por los que transitan unos y otros; a su vez, ese ver, o no querer ver, de los narradores introduce la referencialidad y la evaluación del "mundo de afuera". Se trata de un ámbito que los dos textos desaprueban, en el que los narradores se sienten invisibles, extraños: la frase de Lalo "[m]e siento tan ajeno a lo que me rodea que me siento casi en casa" (60) nuevamente es también válida para Levrero. La representación de este espacio remite al problema de las relaciones -y las tensiones- entre estética y política, entre textualidad y referencialidad, el problema de cómo se articulan ambos campos, y así lo señala el narrador de La novela luminosa al describir una escultura: "es simple, blanca, pura, contundente y luminosa. Eso no se puede conseguir con la literatura [...] La novela luminosa no puede ser una novela; no tengo forma de transmutar los hechos reales de modo tal que se hagan "literatura" (222-435).

En Lalo, la oposición visible versus invisible es política: implica en términos generales Primer Mundo versus Tercer Mundo, aunque incluye todo espacio olvidado, "invisibilizado" por los centros de poder político y cultural: "Puerto Rico es invisible en España. Nuestro gentilicio es la imagen máxima del mínimo espesor, de lo que no despierta interés ni atención. La invisibilidad del mundo le permite a ciertos pueblos la simplificación del mundo" (67).

Revista Iberoamericana, Vol. LXXXII, Núm. 257, Octubre-Diciembre 2016, 805-818 ISSN 0034-9631 (Impreso) 
Sin duda, los narradores comparten un mismo gesto: se escribe para conjurar la invisibilidad o volver invisible un mundo hostil. En ambos, la inmersión en los libros, en la escritura, la obsesión por la computadora -en el caso del texto de Levrero-permiten dar la espalda al insoportable ruido de la ciudad, a la estupidez de los transeúntes y de los shopping, a la pesadilla y la banalidad en que se ha convertido la vida en los comienzos del siglo XXI. Lalo le pone palabras al fastidio y el repliegue del narrador de La novela luminosa quien, obsesionado por los programas de computación y por observar el largo proceso de descomposición del cadáver de una paloma en la terraza, sufre de agorafobia y evita enfrentar la vida urbana. Lalo recuerda cómo ese mundo sólo puede ser inteligible a través del lenguaje y define ese trabajo como un

hacer literatura de viaje sobre la ciudad de la que no se ha salido [...] El viaje inmóvil o, acaso, la circunvalación del hastío. Por eso es por lo que esta ciudad pertenece a la escritura. Territorio de ficción, territorio observado y pensado como se tiene que pensar un desierto o una selva para que no terminen venciéndonos, para sobrevivir en las regiones más extremas del planeta. (146)

Territorio sin duda adverso en el que no vale la pena detener la mirada en casi nada, en el que los ciudadanos, las cosas, los sonidos, son sólo manifestaciones agresivas de un mundo ajeno y casi incomprensible. Dice el narrador de La novela luminosa: "Estos paseos por algo muy parecido al infierno me producen una sensación de irrealidad [...] la Intendencia participa en esta producción de ruido estupidizante; y me imagino lo que será el país dentro de algunos años... el reino de la guarangada y la patota y seguramente un nuevo terrorismo de Estado" (337-38). ${ }^{8} \mathrm{Y}$ a la vez, leemos en el texto de Lalo un eco de lo anterior: "En el camino quedo detenido entre carros que tienen sus radios a todo volumen, creando una especie de generalizada agresión" (162).

En efecto, el modo en que se anuda estética y política se vuelve una cuestión clave en ambos relatos, en tanto el elusivo modo de representar a esta última se sostiene gracias a un trabajo de escritura centrado en la enunciación, en una voz cuya complejidad borra -y problematiza- los límites convencionales reconocidos por la crítica para esa categoría. En ese sentido, el sujeto narrador, ese autor ficticio, esa "ficción de autor", es una estrategia clave para el análisis del registro político. ${ }^{9}$ Más allá de ser sólo un puro juego ficcional antirrealista o un alter ego del autor, plantea

8 Esta es una de las pocas referencias directas a la dictadura militar terminada unos pocos años antes. Otra señala el mismo sentimiento de indefensión frente al Estado que en los tiempos de horror: "Pienso que esta incapacidad del Estado para defender a los ciudadanos es un poco mejor que la agresión a los ciudadanos desde el Estado, como en los tiempos de la dictadura" (210).

9 El narrador-autor de Levrero afirma al hablar de la literatura: "muchas veces yo he dicho y escrito: Si yo quisiera transmitir un mensaje ideológico, escribiría un panfleto [...] Pero eso no quiere decir que en mi literatura no se expongan ideas, y que no valga la pena mencionar esas ideas" (124, énfasis del autor).

Revista Iberoamericana, Vol. LXXXII, Núm. 257, Octubre-Diciembre 2016, 805-818 ISSN 0034-9631 (Impreso)

ISSN 2154-4794 (Electrónico) 
otras posibilidades de lectura en textos como éstos en los que parece sostenerse en un delicado y ambiguo equilibrio.

Este personaje-autor complejiza las relaciones con la referencia y las cuestiona; se diría que propone un paso más allá en el debate que corrió a lo largo del siglo XX sobre la figura del autor. En ella también cobra fuerza una forma de llevar adelante la significación política de un texto, es decir, ese sujeto ejerce una doble atracción: insiste en recordar que es escritura y a su vez su mirada hacia el mundo exterior lo evalúa y lo define como hostil y degradado. Es el espacio donde -retomando a Rancière- la distancia estética se muestra como política. Esa figura del narrador-autor es una forma de representar lo político; se trata de una configuración que dice lo político a través de su forma estética.

En ese cruce se construye un espacio en el que se manifiesta el malestar hacia un afuera donde la vida social parece invivible, en el que se ha quebrado toda alternativa de experiencia colectiva, de solidaridad y de futuro. Justamente, el resultado de este quiebre provoca un repliegue -más que una ausencia- de la emoción frente a la imposibilidad de una experiencia social directa; se produce así un relato marcado por la distancia: el protagonista y narrador vive desgajado y en conflicto con su entorno, en una continua lucha interna con él. Como nos recuerda Agamben:

Sabemos que hoy para efectuar la destrucción de la experiencia no se necesita en absoluto de una catástrofe y que para ello basta perfectamente con la pacífica existencia cotidiana en una gran ciudad. Pues la jornada del hombre contemporáneo ya casi no contiene nada que todavía pueda traducirse en experiencia [...] Vuelve extenuado por un fárrago de acontecimientos [...] sin que ninguno de ellos se haya convertido en experiencia. (Infancia 8)

La opresión de lo cotidiano, su banalidad, es objeto de atención a partir del siglo XIX y se vuelve un tópico problemático durante la modernidad. Agamben señala que el rechazo de la experiencia, en un momento en que se le quiere imponer a la humanidad una experiencia manipulada y predeterminada, puede "constituir - provisoriamenteuna defensa legítima" (12). En ambos textos, la rutina, la ausencia de aventura, de lo extraordinario, la monotonía de la vida cotidiana, la mediocridad y la violencia política, producen el reconocimiento de que la ausencia de salida es la única experiencia posible para el hombre.

El encierro, el extrañamiento, el sentimiento de soledad, son, en ambos relatos, una respuesta, una forma de defensa; ese rechazo frente a un vacío o una ausencia de hechos trascendentes, esa vida que transcurre en un territorio donde nunca pasa nada significativo, señalan ya no sólo un cuestionamiento de un estado de cosas, sino lo absurdo de cualquier esperanza o proyecto. $\mathrm{Y}$ en este sentido es irrelevante que se trate de relatos pertenecientes a países de estatuto político tan disímil: en cualquier caso

Revista Iberoamericana, Vol. LXXXII, Núm. 257, Octubre-Diciembre 2016, 805-818 ISSN 0034-9631 (Impreso)

ISSN 2154-4794 (Electrónico) 
no hay ningún futuro, nada para celebrar ni nadie con quien identificarse. Una cita de Los países invisibles podría encontrarse en La novela luminosa con sólo cambiar el gentilicio: "Me viene a la mente la inclinación de tantos puertorriqueños a celebrarse. Algunos serían capaces de aplaudir en su propia ejecución y, hasta cierto punto, es lo que hemos venido haciendo desde hace décadas" (163).

Sobreviene un sentimiento de distancia e indiferencia con respecto al entorno, a la vida política y social, y al resto de los ciudadanos; la búsqueda de la experiencia se vuelca hacia lo particular e individual. Agamben en “¿Qué es lo contemporáneo?” sostiene que la contemporaneidad es "una relación singular con el propio tiempo, que adhiere a éste y, a la vez, toma su distancia" (18); es decir, se trata de un vínculo que implica una aceptación a la vez que "un desfase y un anacronismo" (19). Ese desacomodo es paradójicamente un signo que define a estos textos y a sus narradores como hijos de su tiempo -épocas poco acogedoras, sin duda-puesto que contemporáneo es aquel "que mantiene la mirada fija en su tiempo, para percibir, no sus luces, sino su oscuridad [...] es aquel que sabe ver esa oscuridad, aquel que está en condiciones de escribir humedeciendo la pluma en la tiniebla del presente" (21).

Ese desfasaje produce el repliegue hacia otras formas de experiencia y de este modo ambos textos apelan al contacto con los libros y las lecturas: en la sección "El viaje" de Los países invisibles, dado que la experiencia misma del viaje es imposible porque "ya no queda nada, sino la copia ruin de un original arruinado" (14), ciertas ciudades son oasis donde se da "la intensificación de la experiencia, porque allí se encuentran las minas de libros" (50). A su vez, "el experimento" que da título a la tercera sección consiste -como ya se dijo- en la experiencia de no comprar libros; el narrador decide escribir sobre "esta forma de miseria, sobre este destino" (99). El registro de libros, eje de todo el texto, se vuelve obsesión en este fragmento y la frase "los libros me protegían [...] de la ciudad desnuda, de la ciudad sin más, sin esperanza, sin lectores" (112), vale, nuevamente, para La novela luminosa, cuyo narrador podría haberla dicho.

Sin embargo, este último relato tiene su origen en el intento -frustrado, fracasadode llevar al papel una experiencia personal "de gran trascendencia" cuya naturaleza jamás se explica; leemos en la primera página:

Yo había narrado [a un amigo] una experiencia personal que para mí había sido de gran trascendencia [...] De acuerdo a mi teoría, ciertas experiencias extraordinarias no pueden ser narradas sin que se desnaturalicen; es imposible llevarlas al papel. (17) Todo este libro es testimonio de un gran fracaso [...] los hechos luminosos, al ser narrados, dejan de ser luminosos, decepcionan, suenan triviales. No son accesibles a la literatura, o por lo menos a mi literatura. (23)

De este modo, la novela no podrá completarse, quedará trunca y jamás conoceremos esa experiencia que provocó la escritura. El prólogo -las quinientas páginas del

Revista Iberoamericana, Vol. LXXXII, Núm. 257, Octubre-Diciembre 2016, 805-818 
diario de la beca- cubre ese hueco, esa experiencia que es imposible escribir y cuyas características desconocemos. El minucioso registro de lo rutinario y cotidiano la sustituye: el relato de lo nimio reemplaza lo extraordinario.

En ambos textos, el mundo de los libros es uno de los pocos espacios en el que los narradores se sienten cómodos; la escritura parece sin embargo un problemático refugio, en particular en Levrero, puesto que está invadida por la imposibilidad, por la pulsión contradictoria de escribir versus no escribir. A su vez, en Lalo, la escritura es el muro, el retén que proteje de la hostilidad de lo real; ${ }^{10}$ pero, en la medida en que el narrador pertenece a un mundo invisible, llevará la marca de la misma invisibilidad:

El pensamiento es un acto de supervivencia; le permite a ciertos hombres y mujeres vivir hacia dentro en un mundo en el que apenas pueden encontrarse. Por esto es por lo que la escritura y el pensamiento poseen la naturaleza imaginaria de una cofradía $[\ldots]$ en ambos casos, es una actividad que se da como respuesta vencida ante la vida. (29, énfasis del autor)

Leer y escribir parecen ser las prácticas - por momentos agónicas- que permiten alguna forma de experiencia, las únicas con las que se alcanza alguna plenitud. En ellas se encuentran las huellas del fracaso político en Los países invisibles y de la huida del mundo en La novela luminosa. Leer y escribir son la contracara del "excesivo deseo de no-participación" (60) que observa en sí mismo el narrador de Lalo mientras se encuentra en un evento social. ${ }^{11}$ La escritura como espacio dominante alcanza otra coincidencia en ambos autores: su centralidad se subraya literalmente en el fragmento "la escritura rayada" que en el trabajo anterior de Lalo, donde, define el fracaso y la invisibilidad del mundo caribeño:

La primera palabra escrita, lo que Colón escribió con tinta en su bitácora, no fue "canoa", sino eanoa [...] Nacimos para ser rayados. Nuestros textos, este mismo que ahora escribo, se inscriben en una tradición que desde su primer día, los niega. Escribimos para decir que muerte y nacimiento es la misma cosa. Juan de Castilla, Điego Colón, Edturardo Lalo. (127)

${ }_{10}$ En La novela luminosa esa función está a cargo de la adicción a la computadora y de los sueños, modos de escape o espacios donde se descifra lo incomprensible del mundo: "Y estas adicciones que me perturban actualmente no son otra cosa que adicciones al estado de trance; un medio de abreviar el tiempo, de que el tiempo pase sin que yo sienta dolor. Pero así también es cómo se me va la vida, cómo mi tiempo de vida se transforma en tiempo de nada, un tiempo cero" (137).

${ }^{11}$ El mismo "deseo de no-participación" y extrañamiento caracteriza al protagonista del diario de $L a$ novela luminosa: "llego a un lugar y ya me estoy despidiendo [...] ya me estoy yendo, incompleto [...] con esa manera de sentir soy extranjero en todas partes. A veces hasta en mi casa, pero esa ya es otra historia" (243).

Revista Iberoamericana, Vol. LXXXII, Núm. 257, Octubre-Diciembre 2016, 805-818 ISSN 0034-9631 (Impreso) ISSN 2154-4794 (Electrónico) 
A su vez, Levrero en Irrupciones cierra el fragmento 8 con el siguiente texto:

Eneontré en el proeesador de textos un botón que, al oprimirlo, permite ir taehando todo lo que se eseribe. Lo interesante de este procedimiento es que permite ir tachando atmismo tiempo que se eseribe. Me siento tentado de seguir eseribiendo así, siempre. (40-41; énfasis del autor)

La escritura rayada y la tachada comparten un mismo gesto autorreflexivo: la obsesiva referencia al acto de escribir permite dar cuenta de diversas formas del fracaso. Ambas son índices de un conflicto, de una angustiosa lucha por existir, por sobrevivir a la invisibilidad, a la borradura política y literaria. ${ }^{12}$

La escritura ha pasado a primer plano, el foco en ella permite protegerse del "afuera" que se distingue por sus múltiples formas de hostilidad; permite también una distancia que obtura la emoción, ayuda al repliegue de los sentimientos -muy evidente en La novela luminosa - y su represión o desplazamiento. Si, como señala Agnes Heller en su Teoría de los sentimientos, "sentir significa estar implicado en algo" (15), podemos pensar que la distancia y/o aislamiento de los narradores equivale a un intento de evitar el sufrimiento: la distancia modifica la perspectiva y neutraliza la empatía; la reacción emocional ante los acontecimientos se vuelve menos comprometida o al menos permite el distanciamiento crítico. El narrador asume una posición de testigo u observador, esquiva entonces sentirse afectado por un mundo agresivo e injusto. ${ }^{13}$

Heller analiza en el libro mencionado la representación de la crisis del mundo burgués de los sentimientos en novelas como El proceso de Kafka, La montaña mágica de Mann y El hombre sin atributos de Musil. Encuentra que en el caso de Kafka, por ejemplo, se plantea una escisión entre el mundo interior y el exterior de modo que la vida interna desaparece; esta discrepancia se expresa en la casi total cesación de expresión emocional. Heller concluye que este vínculo entre interior y exterior "no es simplemente su solución individual, sino que más bien expresa el mundo burgués

12 Los textos de ambos autores despliegan una verdadera pasión por referirse al acto de escribir, a su dificultad, a la impotencia ante la página en blanco, a su inutilidad, etc.: "La escritura rayada es el patrimonio cínico (y nunca el cinismo fue más cruel) de los pueblos vencidos que han formado la periferia de Occidente [...] Escribo con mi pluma fuente, en un cuaderno, en una ciudad que Occidente ignora, las letras inútiles y libres" (donde, 131-32). Y en Levrero: "Creo que no debo seguir escribiendo en este estilo. Voy a esperar hasta que tenga algo para contar, algo con un mínimo de argumento, y trataré de contarlo como se debe" (Novela luminosa 208) y "[e]sto es un ejercicio caligráfico, y nada más. No tiene sentido preocuparse por darle un contenido preciso. Sólo llenar una hoja de papel con mi escritura" (Discurso vacio 107).

13 Esto es particularmente válido para el protagonista de La novela luminosa: "Mi estrategia de aire acondicionado, novelas policiales y computadora me mantuvo en estado de trance permanente [...] No se puede tenerlo todo, y si consigo eliminar el sufrimiento pierdo simultáneamente una cantidad de otras cosas" (385).

Revista Iberoamericana, Vol. LXXXII, Núm. 257, Octubre-Diciembre 2016, 805-818 ISSN 0034-9631 (Impreso)

ISSN 2154-4794 (Electrónico) 
del sentimiento" (251). Podría señalarse que los textos de Levrero y Lalo plantean la relación opuesta: la narración se vuelca hacia la interioridad y su registro es minucioso, aunque desprovisto de sentimentalidad. Sin embargo, el "inventario" de la emoción privada es uno de los problemas que enfrentan los sujetos que enuncian su historia; de este modo, en Levrero leemos: "Quiero sentir, quiero ver las escenas que estoy narrando $[\ldots]$ es necesario que, desde este diario íntimo, busque el camino de mis sentimientos reviviendo hechos más recientes, casi diría fresquitos" (100, énfasis del autor). El lector comprenderá más adelante que a este proyecto sólo le espera el fracaso. A su vez, en Los países invisibles, la comprobación de la distancia entre su manera de ver el mundo y el entorno en el que vive, sume al sujeto en la tristeza: "nos detenemos en un restaurante Pollo Tropical, en un centro comercial de Carolina [...] por las vidrieras se ve el tráfico interminable de la carretera [...] Nos miramos por unos segundos y hay una tristeza indecible. Algo bajo, reptante, que nos come por dentro" (92); "invisibilidad y tristeza" (95) parecen entonces definir la emotividad del narrador.

Podría concluirse que en los comienzos del siglo XXI y en este capitalismo tardío y global, el repliegue de la emoción hacia la interioridad y el relato de lo nimio representan un nuevo estado de cosas: el fracaso de la experiencia social y de los proyectos políticos frente a la pérdida de las esperanzas utópicas. Los sujetos no se sienten implicados en ese mundo y retiran su afectividad, sufren un proceso de extrañamiento. El relato de la "historia mínima", de lo banal, su constante repetición, es la estrategia a la que recurre el texto: ${ }^{14}$ la escritura se ocupa entonces de reiterar y registrar lo "micro", refugio frente a una macrohistoria de la que no es posible más que sentirse desterrado. Repetir y refugiarse en lo nimio será entonces una manera de protegerse, no involucrarse, no sufrir, frente a una realidad que frustra, agrede y no permite esperanza.

El repliegue de los narradores, el rechazo de todo centro cultural, social o político hacia alguna forma de margen nos lleva a relacionar esta narrativa con discusiones muy actuales en torno a la política, el poder y la ética. Es decir, se pueden leer sus posiciones como representaciones de la degradación que sufrió la práctica política en años de impunidad como fueron los años noventa en América Latina; degradación que produjo confusión y desencanto, y generó la pérdida y el olvido de su sentido mismo como campo de reflexión y praxis simultáneos. ${ }^{15}$ Por este motivo, "pensar lo político"

${ }_{14}$ Señala Heller que "la naturaleza repetitiva de ciertos tipos de actividad es la que puede alterar [las acciones], privándolas de implicación" (18, énfasis mío).

${ }^{15} \mathrm{La}$ necesidad de repensar la política, de buscar nuevas respuestas al desgaste de las prácticas tradicionales y al descrédito sufrido por ella, ha sido uno de los desafíos de la teoría política del presente y encuentra en los ensayos de autores como Georgio Agamben, Alain Badiou, Roberto Esposito, Jacques Rancière, Michel Onfray un espacio de debate imprescindible: en todos ellos se cuestiona la identificación absoluta entre política y poder estatal; piensan lo político "en conflicto" con el Estado y no como términos fusionados e indisolubles; los análisis, más allá de sus diferencias, tienen en común el mismo intento de alejarse de la tradicional mirada que los une indisolublemente. Impolítica, biopolítica,

Revista Iberoamericana, Vol. LXXXII, Núm. 257, Octubre-Diciembre 2016, 805-818 
es ciertamente una expresión cuyo significado irá cambiando según el contexto del que forme parte:

En el pensamiento de las últimas décadas, la noción de lo político se hace progresivamente borrosa [...] a este fenómeno corresponde la sensación generalizada de "muerte de la política" o, cuanto menos [...] de una actitud ante la política como actividad de escaso valor [...] La ausencia de noción definida, la incertidumbre en la práctica y la sensación de pérdida de sentido o de inanidad son fenómenos convergentes, que apuntan a una transformación de nuestro tiempo. (Sevilla 268)

Estos narradores no se plantean ya una confrontación o una búsqueda de nuevas formas de actividad política; por el contrario, el retroceso frente a la acción, el fracaso de toda experiencia, provoca el repliegue en un sentimiento de interioridad. Es aquí donde podemos pensar en la aparición de una estética de lo nimio.

Lo nimio se manifiesta en la narración distanciada -en muchos casos desprovista de todo tipo de emoción- de los detalles y acciones aparentemente banales. En todos los casos, lo nimio reemplaza el relato de posibles hechos y episodios "importantes" que no se producen o se los vive como vacíos de sentido; es en sí mismo una reflexión -en la doble acepción de pensar y reflejar- de situaciones y sentimientos ausentes o inexistentes. Lo nimio es lo que pasa cuando no pasa nada, es la forma de la experiencia cuando la emoción se sustrae al afuera, se retira el afecto del mundo social y el sujeto se repliega ante la carencia de trascendencia de ese exterior. Hay que recordar que lo nimio, según el diccionario de la Real Academia Española, tiene tres acepciones: es lo insignificante, pero también lo excesivo y lo minucioso. ${ }^{16}$ Los textos parecen explorar todas estas alternativas al mismo tiempo, basta con leer el obsesivo relato, ya mencionado, en La novela luminosa de la paulatina descomposición del cadáver de la paloma en la terraza frente a la casa del narrador: narración "objetiva", desprovista en absoluto de todo sentimiento, es, sin embargo, un espejo de la angustia y el sentimiento de muerte y sin sentido que atraviesa todo el "diario de la beca". Asimismo, en Los países invisibles, la descripción de espacios y cuestiones banales exponen a la vez sus sentimientos ocultos y la distancia que lo distingue de un ámbito vivido como extraño:

Estoy aquí ahora $[\ldots]$ pasando calor $[\ldots]$ escribiendo esto mientras escucho a mi lado a dos hombres conversar sobre transmisiones automáticas y modelos de automóviles [...] No estoy particularmente afectado por las circunstancias, porque es larga ya la vida pasada en esta pobreza pavimentada. (130)

metapolítica, los términos son índice de esta búsqueda de respuestas a la necesidad de encontrar nuevos parámetros para pensar lo político.

${ }^{16}$ El diccionario define: "1. Insignificante, sin importancia; 2. Excesivo, exagerado; 3. Prolijo, minucioso, escrupuloso" (DLE).

Revista Iberoamericana, Vol. LXXXII, Núm. 257, Octubre-Diciembre 2016, 805-818 ISSN 0034-9631 (Impreso)

ISSN 2154-4794 (Electrónico) 
El relato de su situación en los centros comerciales o en la carretera número 3 tiene una función semejante al del cadáver de la paloma en Levrero: ${ }^{17}$ las palabras "destrucción" y "sin esperanzas" definen sus emociones y la carretera es un reflejo, una representación de lo que la vida no es: su experiencia entonces es de "cruda invisibilidad" (95).

Lo común, en este contexto, se vuelve lo extraordinario, digno de ser contado; es significante en virtud de su gran insignificancia. Lo banal funciona entonces como un signo de un mundo del cual el sujeto protagonista se siente expulsado, un mundo que le es extraño; vive una especie de exilio interior y establece con el exterior relaciones complejas, de rechazo y tensión. Se trata de un sujeto que articula simultáneamente el vínculo y el quiebre entre lo íntimo y lo externo, entre lo literario y lo político.

Peter Bürger, en su excelente ensayo La desaparición del sujeto, afirma que este sujeto y su actual reconsideración pueden leerse como signo de "un deslizamiento epocal" (16) dentro de la categoría misma. Es decir, estamos ante lo que llama "un campo de la subjetividad" (329; énfasis del autor) que abre un espacio de posibles y nuevas determinaciones para esta figura. Sin duda, ambas obras comparten estrategias "epocales", entre las que el yo, esa enunciación que parece desplazarse continuamente, mantiene en tensión el proceso de escritura y, a la vez, se escinde: entre el yo que escribe y el yo descrito, entre el acto de escribir y ese mundo de "afuera" que se impone y al que rechaza simultáneamente. En resumen, ambos textos tienen en común numerosos procedimientos, pero también un "aire de derrota", no una derrota puntual, relacionada a un episodio histórico preciso (como podría ser la dictadura uruguaya, por ejemplo, en el caso de Levrero); estos relatos plantean una derrota radical a la que se ha llegado sin remedio y en un territorio que resulta un "país invisible" o invivible por el que se transita en perpetuo exilio. Si en ellos existe algo parecido a una resistencia, ella no está destinada a la espera de un futuro mejor y de algún modo utópico, sino que es una pura resistencia a pertenecer, es un acto de exclusión y rechazo del presente tal como es.

En los dos textos, se busca el aislamiento, se opta por una especie de indiferencia o distancia, mientras se demuestra la vacuidad de cualquier celebración del pasado o de esperanza en el futuro; "vivir [...] sin las trampas de la esperanza, es decir, desesperado" (143, énfasis del autor) se dice en Los países invisibles y la consigna vale también, nuevamente, para La novela luminosa. Los conflictivos desplazamientos por las ciudades de Montevideo del protagonista de La novela luminosa y por San Juan en Los países invisibles son sinécdoques de la inutilidad de toda participación o

17 "Esta destrucción que apenas se percibe como lo que dramáticamente es, esta carretera número 3 por ejemplo, es el lugar desde donde debo pensar [...] El sentido de la vida no se halla en la carretera número 3 , en sus centros comerciales, en sus complejos de walk-ups, en la comida incomible de sus restaurantes; pero el sentido de la vida [...] puede encontrarse en esa carretera si se le mira por lo que es, es decir sin esperanzas" (Países 94, énfasis del autor).

Revista Iberoamericana, Vol. LXXXII, Núm. 257, Octubre-Diciembre 2016, 805-818 ISSN 0034-9631 (Impreso)

ISSN 2154-4794 (Electrónico) 
entusiasmo por el actual estado de cosas que, parece quedar demostrado, ha quedado lejos de las ilusiones y los proyectos de los siglos XIX y XX. En la novela de Levrero, la imposibilidad de escribir del protagonista, su dispersión en tareas nimias, su intolerancia a la vida en la ciudad, son índices de la distancia entre el presente y las promesas de un "luminoso" futuro hechas en el pasado; en el caso de Lalo, la pertenencia a un país colonial que ninguna gesta tiene para celebrar o añorar, construye un personaje/ narrador y un mundo doblemente "invisibles". Curiosa coincidencia, el relato de un país que jamás conoció la completa independencia y el de otro, con una historia independiente de casi doscientos años, carecen de fe en todo proyecto político: ese gran porvenir prometido ha quedado en el pasado, nada hay que esperar y la función de la literatura parece ser dejar constancia, replegándose en el espacio de la interioridad, de las máscaras que encubren cualquier forma de complacencia con el presente. ${ }^{18}$ Dos textos - uno de ellos perteneciente a un país de incierto estatuto político y de nula autonomía, el otro emergiendo del horror de un pasado aún cercano- coinciden en la misma mirada. La novela luminosa es la historia de una imposibilidad: la de escribir una novela luminosa; el texto que leemos cuenta esa imposibilidad, se escribe para decir que allí, en el territorio en el que transcurre la vida del narrador, es difícil escribir. Por su parte, Los países invisibles narra la imposibilidad de ser visto, de ser percibido, de ser reconocido si se pertenece a un mundo que sigue siendo colonial. Parece entonces que representaciones semejantes recorren ambos relatos: queda igualmente claro que en los países invisibles las novelas luminosas no son posibles porque en estos espacios los futuros felices han quedado borrados del presente por pasados oscuros, muchas de cuyas sombras todavía nos alcanzan.

${ }_{18}$ Quisiera subrayar que no intento aquí asimilar un relato al otro, sólo me interesa analizar ciertas estrategias comunes, quizá un "gesto epocal", apelando al término usado por Bürger, en dos autores muy distantes entre sí y aparentemente en nada relacionados.

Revista Iberoamericana, Vol. LXXXII, Núm. 257, Octubre-Diciembre 2016, 805-818 ISSN 0034-9631 (Impreso)

ISSN 2154-4794 (Electrónico) 
BiBLIOGRAFÍA

Agamben, Giorgio. “QQué es lo contemporáneo?” Desnudez. Buenos Aires: Adriana Hidalgo, 2011. 17-29.

Infancia e historia. Destrucción de la experiencia y origen de la historia. Buenos Aires: Adriana Hidalgo, 2001.

Alberca, Manuel. El pacto ambiguo. De la novela autobiográfica a la autoficción. Madrid: Biblioteca Nueva, 2007.

Bürger, Petery Christa Bürger. La desaparición del sujeto. Una historia de la subjetividad de Montaigne a Blanchot. Madrid: Akal, 2001.

Donoso Macaya, Ángeles. "Estética, política y el posible territorio de la ficción en 2666 de Roberto Bolaño". Revista Hispánica Moderna 62/2 (2009): 125-142.

Gregg, Melissa y Gregory J. Seigworth. The Affect Theory Reader. Durham: Duke UP, 2010.

Heller, Agnes.Teoría de los sentimientos. México: Coyoacán, 1999.

Illouz, Eva. Cold Intimacies: The Making of Emotional Capitalism. Cambridge: Polity, 2004.

Lalo, Eduardo. donde. San Juan: Tal Cual, 2005.

Países invisibles. San Juan: Tal Cual, 2008.

Simone. Buenos Aires: Corregidor, 2011.

Levrero, Mario. Diario de un canalla. Burdeos, 1972. Argentina: Random House Mondadori, 2013. El discurso vacío. Montevideo: Trilce, 1996. Irrupciones. Montevideo: Santillana, 2007. La novela luminosa. Montevideo: Alfaguara, 2005.

Molero de la Iglesia, Alicia. La autoficción en España: Jorge Semprún, Carlos Barral, Luis Goytisolo, Enriqueta Antolín y Antonio Muñoz Molina. Bern:Peter Lang, 2000.

Morales-Rivera, Santiago. "La imaginación desmadrada de Juan José Millás: humor y melancolía en La soledad era esto". Revista Hispánica Moderna 64/2 (2011): 129-48.

Moraña, Mabel y Ignacio Sánchez Prado, eds. El lenguaje de las emociones. Afecto y cultura en América Latina. Madrid/Frankfurt: Iberoamericana/Vervuert, 2012.

Premat, Julio. Héroes sin atributos. Buenos Aires: FCE, 2009.

Rancière, Jacques. "Las paradojas del arte político". El espectador emancipado. Buenos Aires: Manantial, 2010. 53-84.

Sobre politicas estéticas. Barcelona: Universitat Autónoma, 2005.

Real Academia Española. Diccionario de la lengua española. 2016. <http://dle.rae. es/?id=QVRWQHr>. 11 ago. 2016.

Sevilla, Sergio. Crítica, historia y política. Madrid: Cátedra, 2000.

Revista Iberoamericana, Vol. LXXXII, Núm. 257, Octubre-Diciembre 2016, 805-818 ISSN 0034-9631 (Impreso)

ISSN 2154-4794 (Electrónico) 